\title{
Iniciativas estratégicas contra la piratería del software
}

\author{
Rodríguez, Gladys Stella*
}

\section{Resumen}

La gerencia de los bienes intelectuales es una tarea imperativa en esta "era tecnológica", y el software, como producto del intelecto y vinculado con la técnica, exige una estrategia de protección alterna, a los fines de estimular el desarrollo en esta área. El artículo comprende un análisis del principal flagelo que atenta contra el software en la actualidad, como lo es la piratería, por lo que se precisan sus modalidades, sus condiciones, efectos, el comportamiento de las autoridades del software en América Latina, las estrategias para combatirlo. Se rescata, discute y concluye con un conjunto de alternativas para disminuirlo. Palabras clave: Propiedad intelectual, software, técnica, productividad, piratería.

\section{Recibido: 98-05-07 . Aceptado: 98-10-28}

- Doctora en Derecho, Profesora e Investigadora del Instituto de Filosofía del Derecho de la Facultad de Clencias Jjuridicas y Políticas de LUZ en las áreas de Informática Jurídica, Derecho informático y Derecho Internacional Püblico. Dirección Sector Urb. Las Lomas Av. 78". No. 82-56. Maracaibo-Venezuela. 


\section{Strategic Iniciatives to Counterfeiting Software}

\section{Abstract}

The management of intelectual property is an imperative operation in this "technological era", and software, as an intellectual product related to technology, requires an alternative protection strategy, with the purpose of stimulating the development of this area. This article offers an analysis of the principle flagellum affecting software at the moment, piracy. The different modalities of piracy are described, as well as their conditions, the effects, the behaviour of software authorities in Latinamerica, and the strategies used to combat piracy. All of this is reviewed and discussed and the article concludes with a set of alternative stategies to diminish it.

Key words: Intellectual property, software, techniques, productivity, piracy, counterfeiting.

\section{Introducción}

Los programas de computación como una de las máximas manifestaciones del producto "información" han provocado un apuntalamiento de la industria de programación, esto hace que los problemas en torno al software rebasen la esfera puramente técnica, para alcanzar niveles económicos y jurídicos.

El contenido económico de los programas ha suscitado, entre otras cosas, que dichos bienes se constituyan en objeto de inversiones muy altas, asi como de acciones lilicitas de apoderamiento, lo cual ha urgido la búsqueda de soluciones a dichos problemas. En los últimos años ha resurgido con carácter alarmante y como un verdadero delito de sabotaje industrial, comercial y social en el ámbito internacional el "COUNTERFEITING", que se caracteriza por ser una "copia fal- sificada para que parezca tan similar al producto legítimo como sea posible incluyendo la duplicación de la marca o del logo del productor original" (Uscategui, 1996:71), concepto que el grupo de expertos de comercio de "Mercaderías Fabricadas" del GATT, aplica a los productos "que se han copiado en una forma $u$ otra sin permiso y con la intención de engañar o defraudar haciendo pasar la copia por la versión original y auténtica"

"Counterfeiting" es una palabra inglesa, sin traducción precisa al castellano, con la cual se designa recientemente un delito de falsificación de productos de marcas reconocidas, que imita en forma perfecta tanto al producto como a su marca, atentando contra la seguridad y salud públicas y los intereses económicos y fiscales tanto del Estado receptor como del Estado productor de bienes y servicios. 
Tal es el desarrollo de las industrias basadas en las obras del intelecto, que las nociones clásicas sobre lo que debía entenderse por "piratería", han sido rápidamente rebasadas por el avance de los medios tecnológicos y por la creciente y desfavorable participación de las personas que se dedican a la ilícita actividad que vulnera los derechos intelectuales de terceros.

Manuel Rodríguez, miembro del Instituto Interamericano de Derecho de Autor (IIDA), Director de la Business Software Alliance (BSA) de Venezuela y Director del Instituto Venezolano de Representación Cinematográfica (Invereci) disertó acerca de la evolución del vocablo "piratería" señalando lo siguiente:

Hasta hace poco tiempo, el "vocablo "plratería" en el ámbito del derecho de autor, se circunscribía a la reproducción no autorizada de los ejemplares que contenian obras del ingenio fueran éstas iiterarias, artísticas o cientificas..., pero la aparición de nuevos soportes materiales y otros logros de la ciencia, tecnologia digital, las transmisiones por satélite, los superconductores, entre otros avances, produjeron un vuelco, al parecer irreversible, en el avance del vocablo "piratería"... extendiéndose el concepto a toda violación de los derechos de explotación patrimonial, importando poco si se realiza con fines lucrativos, o si es para el ámbito privado" (1996:1).

Hoy emerge un nuevo concepto, el "counterfeiting" que se extiende a las obras de intelecto, cuya importancia ha obligado al legislador a conceptualizar y ubicar en un marco específico, a los programas de computación (software).

\section{Modalidades del "counterfeiting"}

Siguiendo la clasificación utilizada por Antonio Millé (1996:4-7), con ligeras adaptaciones, se presentan algunas modalidades de pirateria o "counterfeiting" en el área de programas de computación, a saber:

- Falsificación de ejemplares: Una actividad que está creciendo aceleradamente en el mundo es la imitación de los programas, que suelen tener fidelidad con el original. Un solo operativo realizado el 24 de abril de 1995, en Estados Unidos, permitió el secuestro de aproximadamente 29.000 programas falsificados de MS-DOS 6.2, otro el 12 de junio de 1995 arrojó 52.600 falsificaciones de programas. Se calcula para fines de este año la retención de más de 470.000 copias de programas falsificados, lo cual es un logro significativo, pero sólo representa un porcentaje de las falsificaciones que no son retenidas.

- Reproducción de copias para su posterior venta: Es una actividad muy difundida en Latinoamérica y la ejecu$\tan$ personas inescrupulosas que se dedican a la duplicación y comercialización de esas copias ilícitas. Recurren a ciertos mecanismos para difundir su actividad: se anuncian en los clasificados de prensa; promueven catálogos de software ilícitos que comercializan, pagan pequeñas comisiones por las ventas que le son refe- 
ridas, se agrupan incluso para adquirir el software original que les servirá de "matriz" o para sufragar conjuntamente los gastos que ocasionan el "desbloquear" las barreras técnicas (cerrojos o dispositivos técnicos contra copia, ubicados en uno de los puertos de la computadora) que tienen algunos programas. En si, toda una pequeña mafia organizada y nucieada para dañar a los propietarios del derecho de autor.

- Clubes de usuarios: Son organizaciones de usuarios, algunas realmente numerosas, que se dedican a la difusión ilícita de copias de software; bajo la modalidad del alquiler o préstamo oneroso, proceden a colocar el software para que sea copiado. En otras ocasiones, el intercambio se produce sin pago de alquiler alguno, pero con la misma finalidad.

- Copia del software para uso corporativo: Algunas empresas, con la intención de no adquirir el software que necesitan, compran un solo ejemplar de cada software, el cual instalan en una unidad central de proceso, y proceden posteriormente a efectuar tantas copias como requieran para satisfacer las necesidades de la empresa. Además, de violentar la normativa, estas empresas carecen de una política informática, no tienen auditoría de sistemas y subutilizan los programas que tienen instalados y sus recursos. Esta modalidad es una de las más difundidas y dañinas, ya que si el "counterfeiting" no tiene justificación alguna, menos aún contando con recursos económicos que le permiten la adquisición del software y la asesoria de recursos humanos calificados.

- Copia privada: Es la copia que hacen los usuarios finales individuales. Aunque puede parecer a primera impresión que sus efectos no son tan perjudiciales, estudios y cálculos efectuados la sitúan entre un $20-25 \%$ del total del "counterfeiting" global. El efecto, resulta en daños cuantiosos. Las productoras han implementado politicas comerciales dirigidas a satisfacer las necesidades de ciertos sectores (estudiantes, y otros) con paquetes de software con descuentos de hasta $80 \%$ del precio del mercado.

- Transgresión a los términos de la licencia: Existen varios tipos de licencia, y los términos referidos en la misma deben ser acatados por las partes: a) La licencia más difundida y conocida es la monousuaria, es decir, la que faculta la instalación y uso de un software en un solo equipo; b) La (icencia multiusuaria, es la que permite que el software sea instalado en un servidor para una red de servicio, permitiendo el manejo del software en varias estaciones o puestos de trabajo; c) La licencia multiusuario de uso concurrencial, se diferencia de la anterior, en que la autorización de uso se contabiliza en razón del uso efectivo máximo de un software, que un determinado momento haga la red. Los inconvenientes en el control de este tipo de licencia, generan el que actualmente se aplique poco; d) Licencias corporativas: son los acuerdos contractuales que realizan las productoras de software con grandes usuarios, a los fines de facilitar la ins- 
talación, copia y uso del software. Los términos referidos en el contrato prevalecerán en caso de conflicto.

- Provisión de software sin marca o clones con la compra del hardware: Muchos vendedores de hardware, para poder concretar una venta, ofrecen instalar sin costo alguno todo el software que requiera el comprador. EI vendedor, además de recurrir en una conducta tipificada comercialmente como competencia desleal, fomenta el uso del "counterfeiting" y causa un daño potencial al consumidor (falta de servicio, presencia de virus, ausencia de actualizaciones, entre otras). Esta conducta es altamente rechazable, sobre todo porque resulta muy fácil "obsequiar" lo que no les pertenece.

\section{Condiciones del "counterfeiting"}

La reproducción envuelve dos elementos: a) Debe existir un grado suficiente de similitud objetiva entre los dos trabajos y b) Relación de causalidad entre la creación del demandante y la del demandado, es decir, que ésta fue producida por el uso que se hizo de la obra del demandante. Para que exista reproducción, además de la similitud objetiva, debe existir la prueba de que en efecto el demandado tuvo la posibilidad de conocer o usar la creación del demandante.

Quien alegue la reproducción debe probarla. En los casos de la copia exacta ordinariamente no existe dificuitad; el problema surge cuando el programa de computador es adaptado, como sucede la mayoría de las veces. Tomando como base decisiones extranjeras, en los procesos de violación del derecho de autor, el onus probandi le incumbe al actor en orden a demostrar que el trabajo del demandado es sustancialmente similar al suyo y que aquel ha tenido la oportunidad de copiarlo; la carga de la prueba se invierte para el demandado cuando pretenda demostrar que no ha reproducido la creación del demandante.

Por ejemplo ¿Se podría inferir copia por el hecho de que el programa del demandado produce un resultado similar al programa del demandante? La respuesta es No; el actor debe demostrar no solamente el resultado de los programas, sino también que en realidad su programa ha sido copiado. La Corte Federal de Australia (Melbourne) en una decisión del 7 de agosto de 1989 que tuvo como partes a AUTODESK INC and AUTODESK Australia PTY. LTD vs. CHRISTINE DYASON and PETER VICENT KELLY, ante la presencia de dos programas de computación que realizaban la misma función, sentenció que se había violado el derecho de autor del demandante. El actor había desarrollado un sofisticado programa de computador llamado Auto CAD para la elaboración de planos y diseños en arquitectura e ingeniería. El programa fue vendido en Australia como un paquete que también comprendia un número de dis$\cos$ y una llave de seguridad conocida como hardware lock, dispositivo de protección anticopia que se provee junto con el software, y que se enchufa en uno de los puertos de la computadora. El software interroga el número de serie de la llave durante la ejecución, para verificar la presencia del código especial que lee el número de la serie. 
Sin la llave el programa no realizaba su función. Era posible copiar los discos del programa usando métodos normales, pero no era posible operar más de una copia sino se utilizaba la llave de seguridad. El demandado, observando el trabajo de la referida llave o seguro, elaboró uno alternativo y en el debate judicial argumentó que no existía un grado suficiente de similitud abjetiva entre los dos seguros. La Corte sostuvo que si bien existía una diferencia de forma entre el seguro de Auto CAD y el seguro del demandado Autokey Lock, Cada seguro constituia un programa de computador, cada uno realizaba la misma función y éste era el aspecto esencial de cada programa. Tal decisión, llevó a Rengifo (1996:213-214) a afirmar que, para la Corte de Australia "la función tiene una particular importancia en la definición de un programa de computación y mucha consideración debe ser puesta al concepto de función, para determinar si hay un grado suficiente de similitud objetiva entre los dos seguros... en este caso la forma de reproducción es irrelevante".

Para la Corte Australiana la diferencia en la apariencia física no contó; por el contrario, fue la función de los programas la que determinó la similitud. Mr. Kelly (el demandado) conoció la función de Auto CAD Lock, descubrió como se realizaba su función y preparó la expresión de su propio conjunto de instrucciones para el Autokelly CAD Lock con el fin de que éste desempeñara idéntica función. En esto consiste la imitación ilegal de los programas de computación.

Hardware lock o llave de hardware, es un dispositivo de protección anticopia que se provee junto con un software, y que se enchufa en uno de los puertos de la computadora. El software interroga el número de serie de la llave durante la ejecución para verificar la presencia del código especial que lee el número de serie.

\section{Efectos del "counterfeiting"}

El "counterfeiting" hoy, está provisto de la más sofisticada tecnología. A primera vista, frente al elevado costo de! software, el "counterfeiting", sólo ofrece ventajas. Pero de acuerdo a la BSA, los riesgos derivados de la copia no autorizada son múltiples. Este oscuro negocio es capaz de facilitar la circulación de millones de copias ilícitas en el mercado y generar una serie de riesgos para todos los ámbitos de la comunidad, siendo los principales los siguientes (Antequera, 1990):

- Técnicos: el software ilícito puede estar infectado con virus que dañen la máquina de usuario o la información que haya en ella. También este tipo de programas suele carecer de manuales, garantía o soporte técnico y muchas veces es incompleto.

- Económicos, Sociales y Culturales: la reproducción ilegal de los programas genera repercusiones insospechadas en un sector de la economía, tales como pérdidas millonarias en dólares sufragadas por los productores $y$ distribuidores de software; auge en los niveles de competencia desleal; baja inversión en investigación y desarrollo en el área, descenso en los niveles de transferencia de tecnologia; incremento del contrabando, elevados índices de evasión fiscal, entre otros, que incide sobre el área social 
(fuentes de empleo), la cultural (creatividad nacional) y el avance hacia una superación científica y tecnologica.

- Fiscales: el auge del "counterfeiting" y en general de toda reproducción ilícita merma los ingresos del erario público, por evasión imposítiva.

A los anteriores se agegan los dos propuestos de Telléz (1996:87) a saber:

- El Despilfarro: la falta de protección ha provocado que las empresas creadoras de software destinen, sumas considerables de dinero para desarrollar programas similares (si no iguales) a los de sus propios competidores, lo cual redunda en un ofrecimiento desmedido de programas para determinadas áreas en detrimento de otras tantas, asi como un precio elevado del producto, estas dos consecuencias menoscaban los intereses de los usuarios informáti$\cos , y$

- El Pillaje: La lucha para dominar el mercado de programación en la industria informática por parte de las empresas especializadas, y aún por los propios intereses de los particulares, genera un sinnúmero de acciones que tienden hacia un apoderamiento dentro de los "términos" más técnicos posibles, a través de métodos directos o indirectos, sofisticados o no, de mala o aún buena fe; para ello utilizan desde el robo, espionaje industrial, chantajes físicos o morales, etc. lo cual ha propiciado una búsqueda desesperada de soluciones por parte de los creadores de programas.

\section{La Industria del software en América Latina ante el counterfeiting}

El principal problema con el software es que por su naturaleza, la duplicación es muy sencilla y de costo infimo. Dando por sentado que una persona posee computadora, copiar un programa sólo le costará unos disquetes o a lo sumo un $C D$ virgen. Además, a diferencia de la "piratería" de cintas de vídeo o música, la precisión e integridad no disminuye con las copias sucesivas de software. La copia 10001.000 sigue siendo idéntica al original.

La tasa promedio del "counterfejting" en Latinoamérica asciende al $80 \%$, lo que en términos prácticos significa que de cada cinco productos de software que se instalan en la región, cuatro fueron adquiridos ilegalmente, esto fue confirmado por Jeffrey Steinhardt, Vice - Presidente y asesor legal para América Latina de la Business Software Alliance (BSA), organización internacional que lucha contra la piratería del software, a través de programas en más de 60 países de Asia, Europa y América, se halla integrada a escala mundial por las siguientes empresas: Adobe Systems, Autodesk, Bentley Systems, Lotus, Microsoft, Novell, The Santa Cruz Operatión y Symantec (PRODUCTO, 1997:56)

A mediados de mayo de este año, el Departamento de Comercio del gobierno de Estados Unidos dió a conocer la nueva lista de países que, a su criterio, atentan contra los derechos de propiedad intelectual. En tal informe Argentina, Ecuador y Paraguay están en la categoría de países bajo observación prioritaria, 
Estrategias contra la piratería del software Rodriguez, Gladys Stella

lo que significa que se detectaron fallas serias en las leyes de protección a esos derechos, o barreras de acceso al mercado especialmente problemáticos. Además, otros 11 paises de la región -entre ellos Brasil y Chile-figuran bajo observación y sólo en México y Uruguay hubo una evolución favorable en la materia.

Otro informe intitulado "Niveles de piratería", publicado por la Consultoría Price Waterhouse también de mayo 1996, revela que en la opinión de los expertos, de reducirse la incidencia del "counterfeiting" de software en la región, la industria del soltware podría lograr un crecimiento aproximado del $400 \%$ para el año 2000. La mayoria de los expertos identifican el "counterfeiting" como el obstáculo principal al desarrollo de la industria del software local y ve a la lucha para erradicarla como uno de los factores que más impactarán a la industria en los próximos años (Rodríguez, 1996).

Para la elaboración de los informes emitidos tanto por el Departamento de
Comercio de E.E.U.U como por la Price Waterhouse, se consultaron más de 100 fabricantes de equipos de computación, productores de software internacionales y locales, y representantes de otras industrias relacionadas.

En 1995 un estudio similar de Price Waterhouse realizado en Europa Occidental concluyó que si los europeos hubieran reducido una tasa de "counterfeiting" o "piratería" de un 50 a un 35 por ciento, habrian recaudado un total de 1400 millones de dólares adicionales en impuestos y habrian creado 56.100 nuevos empleos.

Para Steinhardt, Vice-Presidente y asesor legal de la Business Software Aassociation (BSA), "la falta de protección intelectual limita extraordinariamente la consolidación de una industria de software local. Pero los efectos de la "piratería" trascienden el daño que ocasionan a las empresas productoras. Se trata de un problema serio con implicaciones

\section{Cuadro 1}

Niveles de "Counterfeiting"

\begin{tabular}{lcccc}
\hline \multicolumn{1}{c}{$\begin{array}{l}\text { Países bajo observación } \\
\text { prioritaria }\end{array}$} & \multicolumn{2}{c}{ Soltware de Aplicación } & \multicolumn{2}{c}{ Software de Entretenimiento } \\
\cline { 2 - 5 } & $1995(\%)$ & $1996(\%)$ & $1995(\%)$ & $1996(\%)$ \\
\hline Argentina & 80 & 73 & 84 & 85 \\
Ecuador & 88 & 82 & - & - \\
Egipto & 84 & 89 & 54 & 51 \\
Unión Europea & - & - & - & - \\
Paraguay & 95 & 89 & 95 & 97 \\
Rusia & 94 & 91 & 91 & 93 \\
India & 78 & 78 & 76 & 78 \\
Venezuela & 72 & 70 & - & - \\
\hline
\end{tabular}

Fuente: Departamento de Cornercio de E.E.U.U., 1996. 
profundas para el futuro económico de América Latina" (PRODUCTO, 1996:57)

Los niveles del fenómeno del "counterfeiting" por parte de algunos palses, tanto latinoamericanos como Europeos pueden ser resumidos como se muestra en el Cuadro 1.

Los softwares más copiados son Office 97, AutoCad 14, Photoshop 4.0, por sólo mencionar algunos. En general son programas originales que cuestan entre 200 y 1000 dólares. Los programas copiados responden a la dinámica del trabajo que tenga el usuario de los mismos; sin embargo, es casi una constante la copia de sistemas operativos (MSDOS y Windows 95), procesadores de palabras (Word y WorPerfet), hojas de cálculo (Exel y Lotus 1,2,3), presentador (Power Point), base de datos (Access), sistemas para redes (Windows NT Novell), programas de diseño de obras (AutoCad), antivirus (Norton), diseño de obras (Photoshop y Page Maker) y software de animación. (3D).

La falsificación es un método sistemático en casi todos los países, pero es especialmente elevada en zonas como Hong Kong, Taiwan, Indonesia y la República Popular China, asi como también en Estados Unidos y Europa del Este.

"En Venezuela en 1996, las productoras registraron pérdidas de $109 \mathrm{mi}$ llones de dólares. Si la piratería en Venezuela fuera de 20 por ciento, el fisco dejaria de percibir dos mil ciento ochenta millones de bolivares solamente en impuesto de nacionalización" (PRODUCTO, 1998:44).

Una modalidad de copiado ilegal de software que está en auge en varios países, entre ellos Venezueia, consiste en emplear unidades vírgenes de los productores CD - ROM (que cuentan con una capacidad de $650 \mathrm{Mb}$ ). Esto significa, que ya no se trata de una travesura doméstica sino de un flagrante y alevoso comercio delictual que para ser realizado requiere de cierta estructura tecnológica.

\section{Estrategias para combatir el counterfeiting}

Perú, Venezuela, México, Ecuador y otros paises crean nuevas leyes de marcas comerciales, derechos de autor y patentes, sólo para ver como los "piratas" eluden a los exhaustos sistemas judiciales, la precaria policia y la elevada burocracia. María Strong, Directora de la Alianza de Propiedad Intelectual Internacional (conocida por sus siglas en inglés IIPA), con sede en Washington, DC, ha expresado: "Con la excepción de nuevas leyes en un par de países (Brasil y Argentina) y la revisión de las leyes en algunos otros, ha habido pocos cambios en la situación de los defensores de los Derechos de Propiedad Intelectual (DPI) en América Latina" (1996:100).

Hoy la propiedad intelectual es tan importante para el poder económico como lo eran las tierras en siglos anteriores. El año pasado, las compañías estadounidenses perdieron más de 2,3 millardos de dólares en América Latina como resultado del "counterfeiting" de los productos en general, pero no se obtuvieron cálculos completos de las pérdidas en software, porque no estuvieron disponibles para el momento del estudio de la Business Software Association (BSA).

La situación está cambiando a través de tratados laboriosamente negocia. 
Estrategias contra la piratería del software Rodríguez, Gladys Stella

dos, por agencias como la Organización Mundial del Comercio (OMC); los gobiernos están aceptando la necesidad de proteger la propiedad intelectual. Asimismo, nuevas actitudes y leyes más estrictas se han visto respaldadas por acciones más directas contra los infractores.

Como iniciativas concretas en América Latina, vale mencionar:

- En julio de 1995, Brasil lanzó 11 operativos organizados contra las prácticas del "counterfeiting" de software (PRODUCTO, 1996:100).

- La Policía Federal Mexicana, irrumpió en un establecimiento de Ciudad de México en julio de 1996, incautando millones de pesos en software ilegal (PRODUCTO, 1996:100).

- En Venezuela, para el año (1996) el indice del "counterfeiting" en software alcanzó $72 \%$ de los programas computacionales que se usan en el país. Las pérdidas fueron de $110 \mathrm{mi}$ llones de dólares para las empresas fabricantes de software. Sin embargo, señala Manuel Rodriguez -Director de la BSA-Venezuela- que tras la creación, el pasado 04 de junio de 1996, del Comando Antipiratería (COMANPI), adscrito al "Cuerpo Técnico Judicial", cuya sede se inauguró el 30 de julio del mismo año, se ha participado en la realización de, por lo menos 3 operativos de incautación al mes (1996:116). El COMANPI, trabajando en conjunto con el sector privado (BSA) y estatal (PTJ - DNDA) ha investigado y perseguido a los responsables de los delitos contra el derecho de autor y ha colaborado en las labores de prevención y difusión.
Como resultado de la labor del COMANPI desde su inauguración, el 30 de julio de 1996 hasta el mes de octubre de ese mismo año, ya se habian retenido 15 computadoras, 160 disquetes, 70 programas, 100 compact disk presuntamente ilegales, dos máquinas duplicadoras de CD, carátulas, etiquetas y otros bienes reprográficos. Además, se habían instruido tres expedientes que han pasado a los tribunales penales, quienes han dictado dos auto de sometimiento a juicio.

En el ámbito de las universidades, también hay iniciativas: la Universidad del Zulia el 31 de octubre de 1996 instaló la Comisión Permanente de la Propiedad Intelectual de LUZ y estableció una unidad de competencia compartida entre la Dirección de Asesoría Jurídica, el Consejo Nacional de Desarrollo (CONDES) y el Consejo de Fomento. El propósito es tener una comunidad informada sobre el alcance, proyección e importancia, deberes y derechos a seguir en toda actividad inventiva, lo que permitirá a mediano y largo plazo contar con una cultura sobre propiedad intelectual.

El abismo entre los enunciados de la nueva legislación de los DPI y las evidencias observadas en América Latina son enormes. El "counterfeiting" florece, algunas veces con el apoyo de los gobiernos aún cuando sea ilegal en todas las latitudes. Incluso, en paises donde no existen leyes especificas, los tratados internacionales relacionados con el comercio de los DPI, comprometen a las personas a detener tales prácticas. Pero la situación paradójica -en nuestra opinión- se debe a que se ha construido una fortaleza legal, pero se deja sin vigilancia. Por cada victoria de la Alianza del Software Empre- 
sarial y de sus socios latinoamericanos, muchos casos similares de flagrante plagio quedan impunes.

\section{Panorama latinoamericano}

La Alianza del Software Empresarial considera que el "counterfeiting" está disminuyendo en muchos lugares, pero se estima que $70 \%$ de los programas de computación latinoamericanos son ilegales. En Guatemala la estimación es de $98 \%$.

- Venezuela posee una Oficina de Registro que actúa en forma pasiva y acepta cuanto se le presenta independientemente de sus efectos legales intrínsecos, tanto más en el caso de los derechos de autor registrables en el Protocolo Tercero, para los cuales no se efectúa examen. Aun cuando se crea con la reforma a la Ley sobre derecho de autor, el Registro de la Producción Intelectual, adscrito a la Dirección Nacional del Derecho de Autor (art. 103 ejusdem), en muchos aspectos se sigue la Ley de Registro Público, con atrasos sorprendentes a fines de siglo. L oficina de Registro de Derecho de Autor se ha reducido también, ya que de los 15 Fiscales que este organismo poseía, quedan sólo dos, quienes están en entrenamiento fuera del país. Tampoco existe criterio uniforme en cuanto a qué y cuánto se ha de registrar. Los jueces exigen copia certificada de las obras del ingenio que acredite el registro original en el extranjero, lo que implica abundar inútilmente dentro del campo legal, pues de acuerdo al Convenio de Berna al que estamos adscritos, un bien registrado en el extranjero no requiere registro alguno en el país.

- En Argentina el Presidente Carlos Menem, teniendo como base una ley de 1993, decretó protección para los programas de computación, pero un Tribunal señaló que los softwares no podian ampararse con las leyes de derecho de autor, constituyendo esta situación una visión paradójica,

- Paraguay indicó su intención de revisar sus leyes de los Derechos de Propiedad Intelectual, que datan de la era predigital, y atacó fabricas "piratas"; sin embargo las plantas se reabrieron unas pocas semanas más tarde.

- En México, se suponía que el Tratado de Libre Comercio Norteamericano (TLC), llevaria las normas de propiedad intelectual a los niveles de Estados Unidos y Canadá. Mucho se ha logrado, y por lo menos en teoria, México proporciona una protección relativamente estricta. En este pais, la mayoria de los bienes del "counterfeiting", son software, por lo que el Ministerio de Educación de México reelabora el proyecto de la ley sobre DPI para abarcar los softwares, $C D$ ROM, Internet y otras áreas. No obstante, se cree que los cambios no tendrán mucho efecto, siendo una escena que parece repetirse en la mayoría de los paises latinoamericanos, aun los más privilegiados. Debido a la división de la responsabilidad en diferentes entes como las Fiscalías Generales, encargada de velar por el cumplimiento de la ley, que además no cuenta con suficientes recursos humanos, los procedimientos legales 
arcaicos retrasan las capturas hasta por un mes y luego puede ser demasiado tarde para tomar acciones.

- En Perú, según el representante de Comercio de Estados Unidos, su participación en el Pacto Andino, le proporciona una mejora "global y significativa" en cuanto a normas previas de protección. El Instituto Nacional para la Defensa de las Normas y Protección de la Propiedad Intelectual (Indecopi), es la principal arma contra el "counterfeiting". Fue establecido para proporcionar cooperación en asuntos administrativos, más que penales, a los dueños de derechos de propiedad intelectual. Sin embargo, el "counterfeiting" parece tener la misma presencia que antes en la economía informal de Perú. Fábricas y talleres clandestinos son las únicas fuentes de empleo para miles de personas.

- En Colombia, los funcionarios estadounidenses consideran que las leyes colombianas de protección de los derechos de autor son adecuadas y fuertes. Sin embargo, se falla en su ejecución. La Asociación Nacional de Industriales de Software (Indusoft), informó que $85 \%$ de los programas de computación de Colombia son ilegales. La pérdida para los fabricantes es de 90 millones de dólares.

- En Chile sus leyes antipiratería son rígidas y su sistema judicial es uno de los más eficientes, aunque algunos lo califiquen de "paîs refugio" de los infractores de derecho de autor.

La panorámica latinoamericana destaca que los esfuerzos deben ser asumidos de manera conjunta por los países de las distintas regiones, porque se trata de un problema común, que afecta significativamente el futuro económico de estos paises en vías de desarrollo. Se estima que las pérdidas acumuladas en los últimos cinco años en Latinoamérica ascienden a siete mil trescientos quince millones de dólares. Por ello, en el recién celebrado Foro Colombo-Venezolano "el software y sus implicaciones legales, se hizo énfasis en que el sector público y privado sumen esfuerzos comunes en procura de proteger a la industria del flagelo del "counterfeiting".

Por su parte, el Departamento Administrativo de Seguridad de Colombia, con su grupo de Delitos contra la Propiedad Intelectual también cumple una labor educativa, de seguimiento y represiva, como apoyo a la lucha contra el "counterfeiting" del software. Además, existe una campaña institucional sobre la "Adquisición y uso de software en las entidades gubernamentales de Colombia" iniciada por la Secretaría de Información y Sistemas de la Presidencia de la República de ese pais y dirigida fundamentalmente a capacitar y orientar a los funcionarios públicos sobre la importancia de adquirir y usar software legal.

\section{Foro Binacional Colombo-Venezolano}

El Foro Binacional Colombo-Venezolano "el software y sus implicaciones legales", es un primer paso de cooperación en la lucha contra la piratería o "counterfeiting", realizado en Caracas por los distintos clientes comerciales de América del Sur quienes analizaron la situación y comenzaron a establecer accio- 
nes estratégicas de lucha contra el "counterfeiting".

Este Encuentro respondió principalmente a la idea de que el "counterfeiting" afecta a los intereses comerciales e industriales de los países involucrados, mientras que la producción y comercialización del sottware legal moviliza una industria millonaria en investigación y desarrollo. Además es fuente de empleo, intercambio de divisas e inversiones, por lo cual se ha consagrado que el Estado debe vigilar y garantizar el respeto al derecho de autor de los entes privados, porque de lo contrario se produciría un grave perjuicio a las economías locales y nacionales de los países en desarrollo, asimismo, si los productores de software no pueden ofertar sus productos en un mercado legal, no tendria ningún incentivo continuar desarrollando productos en esta área tecnológica, impidiendo la formación de programadores locales de excelencia.

El "counterfeiting" agrupa a un conjunto de delitos conexos, vinculados con la evasión de impuestos, la estafa y la comercialización ilegal, además de lo previsto en la Ley sobre Derecho de Autor, de alli la importancia de combatirlo radicalmente.

Este encuentro binacional llegó a las siguientes conclusiones:

- La labor conjunta en la lucha contra la piratería de software, permitirá: reducir las ventas y alquiler de material ilegal, aumentar las ventas de la industria legal, consolidar la seguridad jurídica en el país e incrementar la inversión extranjera.

- Establecer políticas claras con los fabricantes del software, que definan convenios de cooperación e información dirigidos a las principales fuentes de consumo de programas de computación.

- Crear centros de información y educación en las universidades y sensibilizar respecto a las repercusiones de tal práctica ilegal a las autoridades, en particular a los cuerpos policiales y al Poder Legislativo.

- Orientar al usuario final para que su compra esté dirigida a la adquisición de software legal.

- Dictar cursos, talleres y entrenamiento a todos los sectores involucrados con la lucha contra el "counterfeiting", tales como: entes policiales, jueces, autoridades civiles, sector privado, periodistas y universidades entre otros.

\section{Propuesta para disminuir el "counterfeiting" del software en Venezuela}

Es necesario educar a la opinión pública, establecer vinculos de cooperación entre los sectores públicos y privados y sensibilizar a las autoridades, así como hacer participar a las universidades en el establecimiento de lineamientos proteccionistas para los resultados de la creatividad humana, configuran un primer y sólido paso en avance contra el "counterfeiting".

Hasta ahora se ha podido comprobar que las leyes por sí solas no son suficientes para erradicar la piratería o "counterfeiting", por muy represivas que éstas sean. En la medida en que se amplian los elementos susceptibles de transmisión, se produce un conjunto de efectos, técnicos y jurídicos, entre otros, que colocan 
en posición de desventaja a la industria de las nuevas tecnologías en general y de la informática en particular. La Ley sobre derecho de autor vigente no brinda respuesta satisfactoria, ninguna ley por si sola es totalmente efectiva, proponiéndose en algunos casos la presencia de elementos técnicos como protectores del software.

Pero la técnica también ayuda a burlar la protección que la misma tecnología ha creado, por lo que, a través de un Reglamento se puede, de manera explicita, consagrar lato sensu la muitiplicidad de especificaciones que comprenden estas altas tecnologías, a fin de establecer acciones como las de: prohibir la importación, fabricación y distribución de dispositivos (o cualquier componente incorporado en los dispositivos o productos), o el ofrecimiento o ejecución de cualquier servicio, cuyo objetivo sea evitar, desviar, eliminar, desactivar o de cualquier otra manera anular los medios técnicos aplicados para proteger los derechos reconocidos por la ley. Recuérdese la decisión de la Corte Australiana en el caso Auto CAD vs Autodeskelly Lock acerca de la denominada "llave de seguridad", cuya copia con el mismo fin constituye un fraude a la ley, y por tanto una conducta prohibida y sancionada.

Tal Reglamento preverá sanciones en caso de fabricación, importación o distribución para venta o alquiler, de aparatos diseñados o adaptados para soslayar dispositivos destinados a impedir o restringir la realización de copias de obras, 0 a menoscabar la calidad de las copias realizadas, o de cualquier otro aparato capaz de permitir o fomentar la recepción de un programa codificado, radiodifundido o comunicado en otra forma al público, por aquellos no autorizados a recibir el programa.

Nuestra propuesta descansa entonces en un plus o conjunto coherente $y$ sistemático de acciones, que requieren el concurso de varios factores, a saber:

- Legislación adecuada: Se debe disponer de una legislación acorde contra el "counterfeiting". Algunos paises requieren modificaciones a sus legislaciones internas en materia penal, para castigar severamente los actos de "counterfeiting" con penas restrictivas de la libertad, que se correspondan con la naturaleza e importancia del bien jurídico lesionado. Parece desacertado que algunos tipos de ilicitos penales contra los bienes intelectuales, tengan una pena menor que las violaciones de la propiedad en el ámbito del derecho común. Las penas para reprimir el "counterfeiting" deben equivaler, al menos, a las previstas para los delitos de hurto y robo. En cuanto al resarcimiento del daño causado, éste tiene que consistir en una condena cuyo monto sea tal que tenga un efecto disuasivo; de manera que se mantenga un equilibrio entre la norma y la conducta social.

- Participación efectiva de los órganos jurisdiccionales y administrativos en la aplicación de la ley: Los funcionarios deben estar dotados de suficiente conocimiento sobre los aspectos legislativos y económicos ligados a los derechos intelectuales; ser capaces de reconocer la importancia que tienen estos derechos para el correcto desarrollo del país, tener la vo- 
luntad de aplicar las normas, y entender que los patrones tradicionales de apreciación sobre la propiedad común no se aplican al derecho de autor. La formulación de las normas debe garantizar un ambiente de seguridad jurídica, indispensable para propiciar las inversiones y estabilidad de las industrias vinculadas al área.

- Campaña contra el "counterfelting": La ejecución de una campaña guarda relación directa con el bien jurídico que se pretenda proteger y con las realidades económicas, políticas, sociales y culturales del país. Los titulares de derecho deben, con el auxilio de expertos en la materia, planificar, estructurar, desarrollar y evaluar, con base a los objetivos y programas implementados, los resultados de la misma. Aun cuando pueden ser variados los esquemas de estas campañas, siempre coinciden algunos elementos comunes, tales como: una fase comunicacional que difunda a través de distintos medios los aspectos ligados a la protección de los derechos intelectuales; una fase de información y formación a los órganos administrativos y judiciales $y$, una fase de carácter judicial que disponga de acciones civiles y penales. El no hacerlo convertirá rápidamente el "counterfeiting" en una industria paralela a la legal.

- Conciencia colectiva: Escaso valor presenta el disponer de los elementos antes indicados, si el colectivo no percibe y aprecia los derechos intelectuales. Este conocimiento de hechos y factores económicos de la industria que demuestran la trascen- dencia de las relaciones comerciales de las cuales son objeto los bienes intelectuales, debe, en poco tiempo, transformarse en un reconocimiento a dichos valores. El rechazo al "counterfeiting" deberia, en la colectividad, ser un elemento intrínseco a cada individuo.

Todo lo analizado hasta ahora ha intentado dar respuesta a cuestiones sobre ¿por qué existe el "counterfeiting?", y ¿cómo pueden protegerse los creadores de software contra la extensión del "counterfeiting" de sus productos?. Llevando a reflexionar acerca de este fenómeno interesante.

Se alega que es probable que sean tres las razones del plagio: su elevado precio, la facilidad con que se puede copiar y la ignorancia de las leyes sobre derecho de autor. Hasta hace poco, los fabricantes de software distribuian sus productos con una "protección contra copia" dentro del propio software. Se diseñaba el software intencionalmente para que no funcionase bien en caso de que se realizase o utilizase una copia ilegal. Los fabricantes, han encontrado varias formas de proteger sus productos contra la duplicación ilegal, pero la mayoría de ellas han sido burladas por usuarios que no terminan de entender que los bienes intelectuales merecen respeto igual que cualquier otra propiedad.

Los fabricantes han abandonado la batalla contra los transgresores y han visto la solución en el aumento de los precios de sus productos de forma que incluya el de cierto número de copias ilícitas. Pero creemos que esta no puede ser una solución sostenible, por lo que aunado a la serie de recomendaciones que se han 
esgrimido a lo largo de este título, la solución tanto para usuarios como fabricantes tendrá que finalizar en una nueva relación, y un componente esencial de esta nueva relación es el control del precio en los términos de las licencias, de forma que sean adecuados para el usuario y a la vez permitan al fabricante recuperar adecuadamente su inversión.

Otro componente esencial es una nueva conciencia y sensibilidad por parte de los usuarios, tanto del costo real de la producción y distribución del software, como de las propias ramificaciones legales y êticas del "counterfeiting".

Finalmente, los mismos abogados y jueces -dejando aparte a los usuarios en general-deben comprender el estatus del software con respecto a las leyes sobre propiedad intelectual y trabajar conjuntamente para resolver el problema del "counterfeiting".

\section{Justificación de la propuesta}

Encontramos que existen avances sorprendentes en el ámbito de la informática y las telecomunicaciones, tales como:

1. Se sustituyen paulatinamente los diversos aparatos de trabajo o domésticos -el televisor, los equipos de sonido y vídeo, la máquina de escribir, el teléfono y el fax-, por un sólo aparato que funcionaría a manera de un "superconductor" dotado de una "inteligencia central"

2. Si bien una gran parte de las transmisiones que se reciben por esos medios telemáticos es realizada a partir del almacenamiento o la fijación de la información en un soporte material, la fidelidad de los signos, los sonidos y las imágenes que se logran a través de las comunicaciones a distancia efectuadas por medio de la tecnología digital, avizoran que por lo menos un sector del público necesitará cada vez menos del soporte físico contentivo de las obras, hechos o datos, emitidos desde la fuente de la transmisión hasta el usuario receptor.

3. La mejora cualitativa en cuanto a la recepción de la información, estimulará su grabación privada -incluso el "counterfeiting"--, mediante la posibilidad de realizar copias de la transmisión recibida con la misma calidad de imagen o sonido, que si se efectuara directamente a partir de un soporte digital.

La facilidad con la que se infringen las leyes y la dificultad para detectarlo y hacerlas cumplir, obligará a los titulares de derechos de autor a recurrir a la tecnología, asi como a la ley, para obtener una eficaz protección de sus obras y mediante la ayuda tecnológica se podrán aplicar mecanismos contra el acceso, reproducción, manipulación, distribución, ejecución o presentación no autorizados, lo que ayudará a hacer respetar la integridad de las obras y a la administración y licencia de los derechos. (Secretaría de Comercio de E.E.U.U. (Cit. por Antequera, 1996: 25).

\section{Conclusiones}

El presente trabajo significó un análisis exploratorio de la situación que se plantea con el uso ilícito tanto de programas como de bases de datos en eles- 
cenario de los distintos países; conduciendo al establecimiento de una serie de alternativas estratégicas a fin de erradicar la difícil situación por la que estos bienes del ingenio atraviesan constantemente impulsado por los avances vertiginosos de la tecnología a la que el Derecho debe estorzarse por alcanzar.

- Es válido indicar que el dínamismo y desarrollo de la sociedad contemporánea de fines de siglo, no sólo ha arrojado resultados impresionantes en el ámbito tecnológico, y en particular en la informática, sino que además ha implicado que el derecho asuma una posición sólida capaz de dar respuesta a los complejos problemas del entorno. En este orden, paralelo al desarrollo de la técnica, se ha instaurado una peligrosa industria como lo es el "Counterfeiting" término con el cual se designa recientemente un delito de plagio de software que afecta la seguridad, el bienestar público y los intereses fiscales y económicos tanto del adquiriente del software, del fabricante o productor, así como del mismo Estado.

- Actualmente, las cifras de Counterfeiting son elevadas van desde las más simples (copia privada) hasta las más complejas (copia de software para uso corporativo). En este sentido, también son numerosos los recursos para atemperar este flagelo tales como los de orden legal, económico y hasta fiscal; no obstante, la tasa promedio del "Counterfeiting" en Latinoamérica asciende al $80 \%$, lo cual en términos prácticos significa que de cada cinco productos de software que se instalan en la región, cuatro fueron adquiridos ilegalmente.

- Las leyes solas no protegen a las personas o las propiedades, y algunas de sus modificaciones han confundido más la situación.

- Se propone finalmente un sistema de protección alternativo sobre la base de un plus de acciones, para combatir los índices alarmantes de counterfeiting, más cuando se trata de una industria de grandes alcances en 10 económico, comercial, cultural y social.

\section{Bibliografía citada}

Antequera, Ricardo, (1996) Derechos de Autor y Derechos Conexos. Curso Propedéutico. ULA, Mérida.

Business Software Alliance, (1996) El Zarpazo de la pirateria, Producto pp 83-0184, Año 14. № 157.

Business Software Alliance, (1996) Los nuevos piratas, Producto pp 83-0184, Año 14. № 159 .

Ley de Reforma de la Ley sobre Derecho de Autor. Gaceta Oficial N2 4.638. Extraordinario del $1^{\circ}$ de diciembre de 1993.

Millé, Antonio, (1990) La protección del sottware por Derechos de Autor. Elementos básicos y normativa latinoamericana. La protección jurídica del software y de las bases de datos. IIDA Argentina

OMPI. Acta de París del Convenio de Berna art. 10.1

Rengifo, Ernesto, (1996) Propiedad Intelectual. El modemo Derecho de Autor. Bogotá. Universidad Externado de Colombia. 1 era edición.

Rodriguez, Manuel, (1996) La Piratería como flagelo del Derecho de Autor y los 
Estrategias contra la piratería del software

Rodriguez; Gladys Stella

Derechos Conexos. Merida. Seminario de la OMPI sobre Derecho de Autor y Derechos Conexos. Del 14 al 16 de noviembre.

PRODUCTO (1998) Sottware a dedo. Produc-

to p.p 198302DF126, Año 15. № 172.
Téllez, Julio, (1996) Derecho Informático. México. McGRAW-HILL.

Uscategui, Mariano,(1991) Gerencie sus Bienes Intelectuales. Caracas. Forum Editores, C.A. $1^{\text {edición. }}$ 